\title{
Mover Field Oriented Control of Linear Permanent-Magnet Vernier Motor Considering Loss Minimization
}

\author{
Xianqun Qiu*, Wenxiang Zhao ${ }^{\dagger}$, Qian Chen* and Dezhi Xu*
}

\begin{abstract}
A linear permanent-magnet vernier (LPMV) motor has magnets and windings in the short mover, which is very suitable for long stroke applications. This paper proposed a new field oriented control with space vector pulse width modulation for the LPMV motor, which considers loss minimization. First, the topology of the LPMV motor is briefly presented. Then, the mathematical model is derived, and the mover field oriented control strategy is proposed. Also, the loss analysis is performed. Finally, the simulated and experimental results are given, verifying the feasibility and effectiveness of the proposed control strategy.
\end{abstract}

Keywords: Permanent-magnet vernier motor, Linear motor, Mover field oriented control, Loss minimization

\section{Introduction}

In recent years, linear motors have been widely used in transportation systems and industrial application with significant advantages that not need to launch a mechanical converter from rotational torque to linear force [1-6]. The conventional permanent-magnet (PM) linear motor exhibits higher efficiency and high power factor than the linear induction motor. Thus, it attracts extensive attention of that instead the induction linear motor as train engine. However, the implement suffers from high cost because the PMs or the windings should be placed on the long stator. In order to overcome this shortcoming, a new class of PM motors, whose PMs and windings are located in the same side of the motor, have attracted wide attention [7-12], such as doubly salient PM motors, flux reversal PM motors, vernier PM motors, and flux-switching PM motor. Among these PM machines, the vernier PM motor has significant advantage of high torque/ force capability due to its special magnetic gear flux field modulation [13-15]. A new linear vernier motor was proposed in [16]. This motor incorporates the merits of robust structure, low cogging force, and thermal stability, but it suffers from relatively low force density and high PM usage. To improve force performance, a new linear PM vernier (LPMV) motor has been proposed and investigated [17], in which two magnetization directions of PMs are integrated together, as shown in Fig. 1. Its PMs and windings are located in the short mover, while the long stator consists of an iron core only [18]. Hence, it can reduce leakage flux and enhance force capability. The detailed specifications of the LPMV motor are listed in Table 1.

$\dagger$ Corresponding Author: School of Electrical and Information Engineering, Jiangsu University, China. (zwx@ujs.edu.cn)

* School of Electrical and Information Engineering, Jiangsu University,

China. (xianqunqiu@163.com, \{zwx, chenqian0501,xudezhi\}@ujs.edu.cn) Received: July 14, 2016; Accepted: January 28, 2017
Until now, the researches about LPMV motors are mainly focused on the structure, operation principle and static thrust force performance, rather than the optimal control strategy. Therefore, it is important to investigate a control strategy of the LPMV motor. For induction motors and conventional PM brushless motors, the field oriented control strategy is a common method [19-21]. However, the operation principle and structure of the PM vernier motor are significantly different from these existing motors. Therefore, the question whether the conventional field oriented control strategy is applicable to the LPMV motor

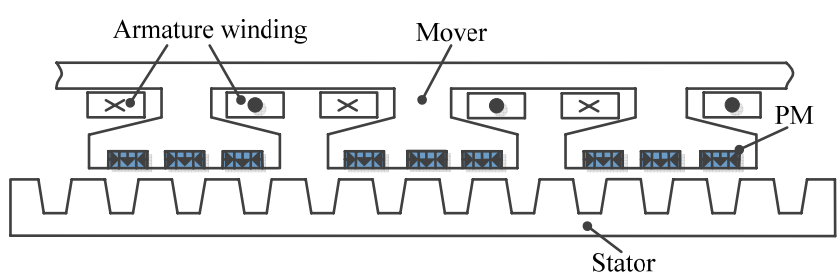

(a)

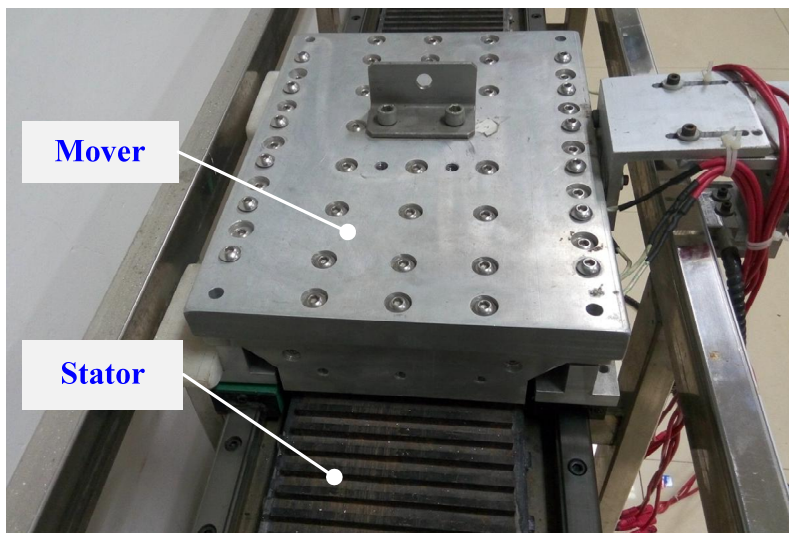

(b)

Fig. 1. Configurations of LPMV motor: (a) Structure; (b) Prototype 
Table 1. Specifications of the LPMV motor

\begin{tabular}{c|c}
\hline Items & Specifications \\
\hline Rated speed, $v(\mathrm{~m} / \mathrm{s})$ & 1.5 \\
\hline Mover width, $w_{m}(\mathrm{~mm})$ & 120 \\
\hline Stator pole pitch, $\tau_{s}(\mathrm{~mm})$ & 49 \\
\hline Mover slot opening, $w_{m 0}(\mathrm{~mm})$ & 2 \\
\hline Mover splittooth width, $w_{m s}(\mathrm{~mm})$ & 5 \\
\hline PM thickness, $h_{p 0}(\mathrm{~mm})$ & 5 \\
\hline Vertically magnetized PM width, $w_{v}(\mathrm{~mm})$ & 5 \\
\hline Horizontally magnetized PM width, $w_{h}(\mathrm{~mm})$ & 2 \\
\hline Stator pole pitch, $\tau_{s}(\mathrm{~mm})$ & 14.7 \\
\hline Stator tooth tip, $w_{s t}(\mathrm{~mm})$ & 5.2 \\
\hline Stator tooth root, $w_{s r}(\mathrm{~mm})$ & 5.7 \\
\hline Stator tooth height, $h_{s t}(\mathrm{~mm})$ & 8 \\
\hline Number of $\mathrm{slot} / \mathrm{pitch}$ & $18 / 20$ \\
\hline Air-gap length, $\mathrm{g}(\mathrm{mm})$ & 2 \\
\hline Magnet material & $\mathrm{NdFe} 35$ \\
\hline Magnet remanence, $B_{i}(\mathrm{~T})$ & 1.2 \\
\hline Current density, $\mathrm{J}\left(\mathrm{A} / \mathrm{mm}{ }^{2}\right)$ & 3.5 \\
\hline Copper mass, $M_{c u}(\mathrm{~kg})$ & 1.8 \\
\hline
\end{tabular}

is unclear.

This paper will investigate a new field oriented control strategy for the LPMV motor by using the space vector pulse width modulation (SVPWM). The SVPWM method has a constant switching frequency, and is beneficial to minimize both the inverter switching loss and the motor eddy current loss [22]. Moreover, the conventional method for the field oriented control adopts $i_{d}=0$ in order to simplify the control task and improve force capability. However, it is not very suitable for the LPMV motor to minimize losses. Numerous control strategies have been proposed in order to improve the performance and reduce the losses of PM brushless motors [23-26], but have never been reported in the LPMV motor. This paper will propose an optimal current control strategy by considering the minimization of motor losses.

The rest of the paper is organized as follows. Section II briefly describes the field oriented control strategy and the analysis of the loss of the LPMV motor, including the definition of the $d$-axis and $q$-axis and the mathematical model. In Section III, the detailed simulations are carried out based on MATLAB/Simulink. Experimental results are reported in Section IV. Finally, Section V gives the conclusions of this research.

\section{Control Strategy}

\subsection{Definition of $D$ - and $Q$-axis}

Fig. 2 shows the simulated back-EMFs of the LPMV motor at the rated mover speed of $1.5 \mathrm{~m} / \mathrm{s}$ and the measured back-EMFs at the mover speed of $1.44 \mathrm{~m} / \mathrm{s}$. Since the back-EMF is proportional to the speed, the simulated back-EMF at the mover speed of $1.44 \mathrm{~m} / \mathrm{s}$ can be calculated as $60.4 \mathrm{~V}$. Of course, there is still slight

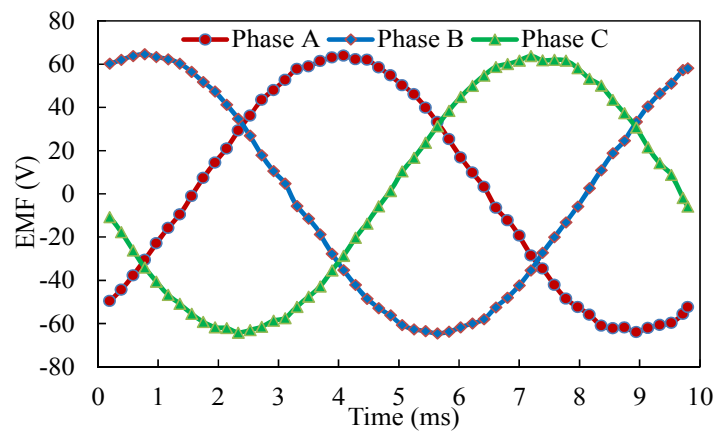

(a)

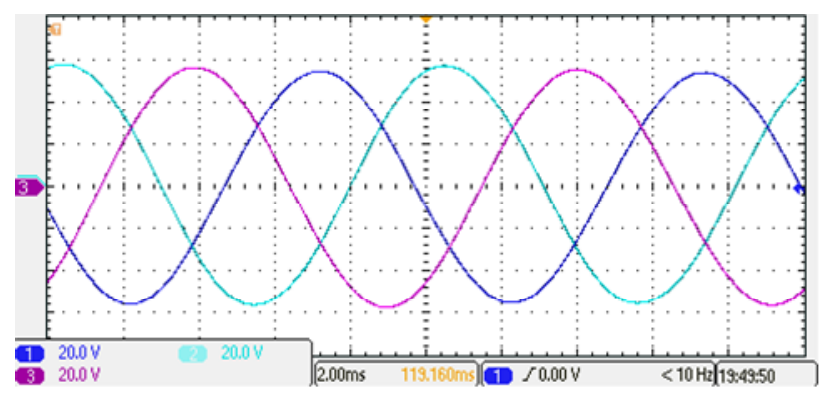

(b)

Fig. 2. Back-EMF waveforms of LPMV motor: (a) Simulated one; (b) Measured one

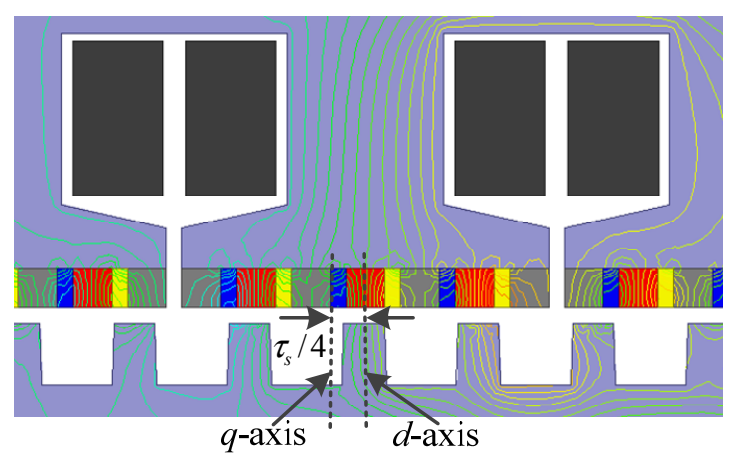

Fig. 3. Definitions of $d$ - and $q$-axis

difference between the simulated and the measured results due to the manufacturing error. It can be seen that these waveforms are very sinusoidal and symmetrical. Since the field oriented control strategy should be based on the synchronous mover frame, the $d$ - and $q$-axis of the LPMV motor is necessary. They can be defined as illustrated in Fig. 3. When the PM flux linkage reaches the maximum value, the mover position is defined as the $d$-axis. Meanwhile, when the value of PM flux linkage became zero, the mover position is defined as the $q$-axis. The relative displacement between the $d$-axis and the $q$-axis is a quarter of the stator pole pitch.

\subsection{Mathematical model}

When it transformed from stator reference to mover 
reference, the total flux linkage and inductance in the $d$ and $q$-axis can be expressed as

$$
\begin{gathered}
\left\{\begin{array}{l}
\psi_{d}=\psi_{m d}+L_{d} I_{d}+L_{d q} I_{q} \\
\psi_{q}=L_{q} I_{q}+L_{q d} I_{d}
\end{array}\right. \\
\left\{\begin{array}{l}
L_{d}=L_{0}-M_{0}+\frac{1}{2}\left(L_{M}+2 M_{M}\right) \cos 3 \theta \\
L_{q}=L_{0}-M_{0}-\frac{1}{2}\left(L_{M}+2 M_{M}\right) \cos 3 \theta \\
L_{d q}=-\frac{1}{2}\left(L_{M}+2 M_{M}\right) \sin 3 \theta
\end{array}\right.
\end{gathered}
$$

where $\psi_{m d}$ is the peak value of the PM flux linkage, and $\theta$ is the electrical degree of the mover position; $L_{0}$ and $L_{M}$ are the dc component and the peak value of the fundamental component of self-inductance, respectively. $M_{0}$ and $M_{M}$ are the dc component of mutual-inductance, separately.

The voltage equations in the $d$ - and $q$-axis can be defined as

$$
\left\{\begin{array}{l}
u_{d}=\frac{d \psi_{d}}{d t}-w_{e} \psi_{q}+R I_{d} \\
u_{q}=\frac{d \psi_{q}}{d t}+w_{e} \psi_{d}+R I_{q}
\end{array}\right.
$$

By substituting (1) and (2) into (3), the voltage equations can be obtained as

$$
\left\{\begin{aligned}
u_{d}= & -\frac{3}{2} w_{e}\left(L_{M}+2 M_{M}\right)\left[I_{d} \sin 3 \theta+I_{q} \cos 3 \theta\right] \\
& -w_{e} \psi_{q}+R I_{d} \\
u_{q}= & \frac{3}{2} w_{e}\left(L_{M}+2 M_{M}\right)\left[I_{q} \sin 3 \theta-I_{d} \cos 3 \theta\right] \\
& +w_{e} \psi_{d}+R I_{q}
\end{aligned}\right.
$$

where $\omega_{e}=2 \pi v / \tau_{s}$ is the electrical angular frequency, and $v$ is the mover speed.

By neglecting the phase resistance, the thrust force of the three phase LPMV motor can be written as

$$
F=\frac{3}{2} \frac{\left|\left(u_{d} i_{d}+u_{q} i_{q}\right)\right|}{v}
$$

Substituting (4) into (5), it can be obtained

$$
\begin{aligned}
F & =\frac{3 w_{e}}{2 v} \psi_{m d} I_{q}+\frac{3 w_{e}}{v}\left(L_{d}-L_{q}\right) I_{d} I_{q}-\frac{3 w_{e}}{v} L_{d q}\left(I_{q}^{2}-I_{d}^{2}\right) \\
& =F_{p m}+F_{r}+F_{l}
\end{aligned}
$$

where $F_{p m}$ is the PM thrust force, $F_{r}$ is the reluctance force, $F_{l}$ is the force caused by the inductance.

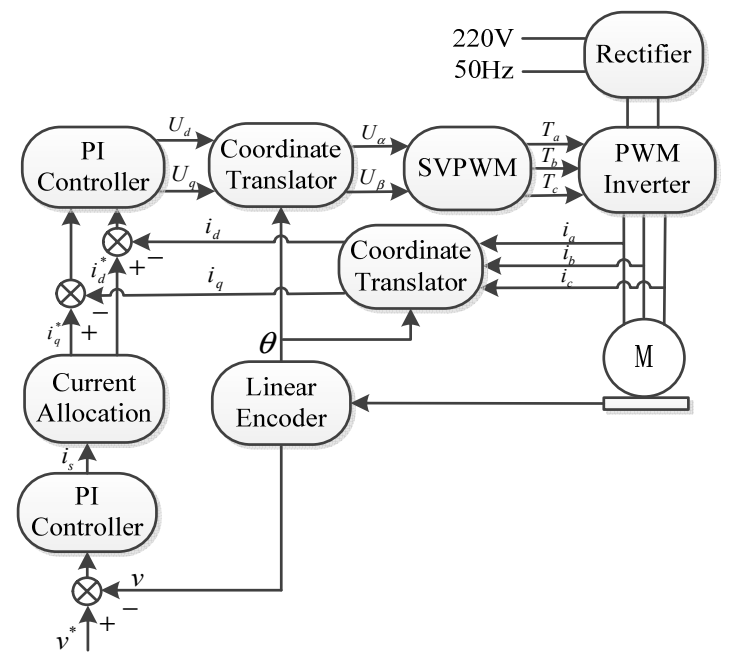

Fig. 4. Field oriented control system

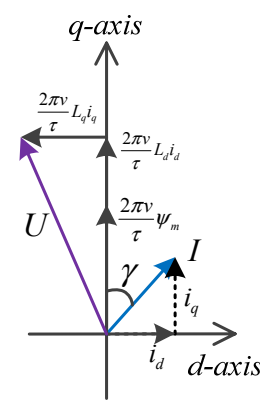

(a)

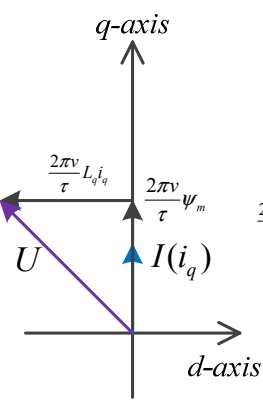

(b)

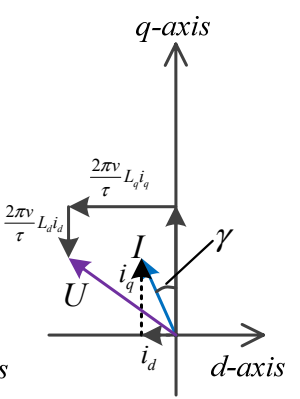

(c)
Fig. 5. Vectors in three different modes: (a) Current hysteresis mode; (b) $i_{d}=0$ mode; (c) Current advance mode

\subsection{Mover field oriented control}

The proposed field oriented control for the LPMV motor adopts the loss minimization technique as shown in Fig. 4, in which $v^{*}$ is the speed command, $i_{d}{ }^{*}$ and $i_{q}{ }^{*}$ are the $d$ - and $q$-axis command currents, $i_{a}, i_{b}$, and $i_{c}$ are the three-phase currents, $T_{a}, T_{b}$, and $T_{c}$ are the switch signals of the inverter. The drive system consists of linear encoder, PI controller, current allocation, coordinate translator, SVPWM, PWM inverter, power source, and LPMV motor. The mover position and speed can be determined by linear encoder.

The sector of current allocation divides the state current into two parts of $i_{d}{ }^{*}$ and $i_{q}{ }^{*}$, which can be derived as

$$
\left\{\begin{array}{l}
i_{d}^{*}=i_{s} \sin \gamma \\
i_{q}^{*}=i_{s} \cos \gamma
\end{array}\right.
$$

where $\gamma$ is a deviation angles from the current vector to the $q$-axis. $i_{d}{ }^{*}$ and $i_{q}{ }^{*}$ represents the magnet component and torque component, respectively.

Fig. 5 shows the vectors of three modes of state current control strategy. $U$ and $I$ are the voltage vector and the 
current vector, respectively. When $\gamma>0^{\circ}$, the motor operating in the current hysteresis mode as shown in Fig. 5(a). Also, $\gamma=0^{\circ}$ represents $i_{d}=0$ mode, as shown in Fig. 5(b), while $\gamma<0^{\circ}$ represents current advance mode as shown in Fig. 5(c).

\subsection{Loss analysis}

Neglecting the losses due to the switching frequency harmonics in the air gap magnetic motive force, the total losses in the motor comprises of the mechanical losses, copper losses, and the iron losses in the mover and the stator circuits. Since the mechanical losses mainly derive from the motor friction, which is uncontrolled, the following investigation will focus on the controllable electrical loss. The steady state space vector equivalent circuits of the motor in the $d$-and $q$-axis frame of reference is shown in Fig. 6, in which $R_{s}$ and $i_{s}$ are the stator

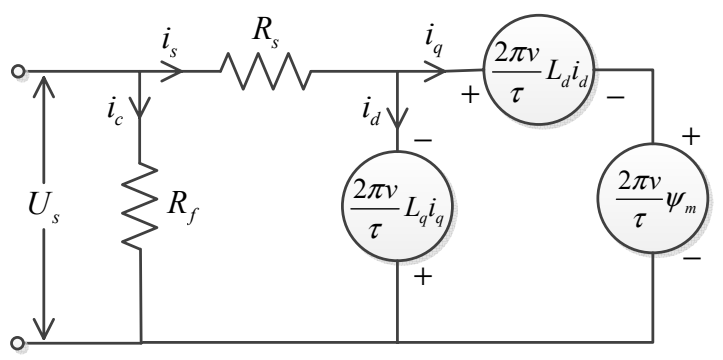

Fig. 6. Space vector equivalent circuit in $d$ - and $q$-axis frame

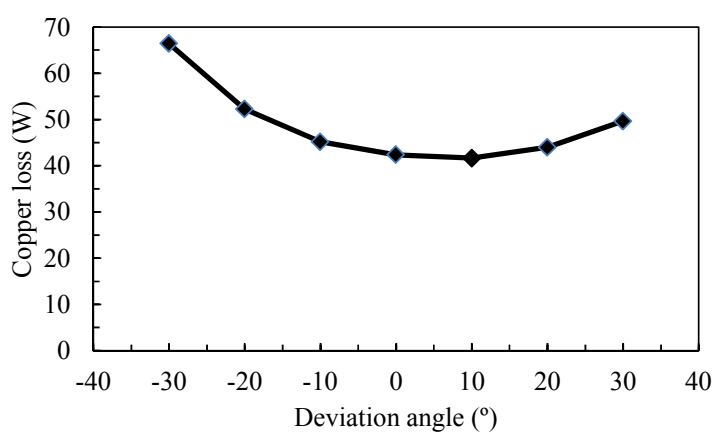

(a)

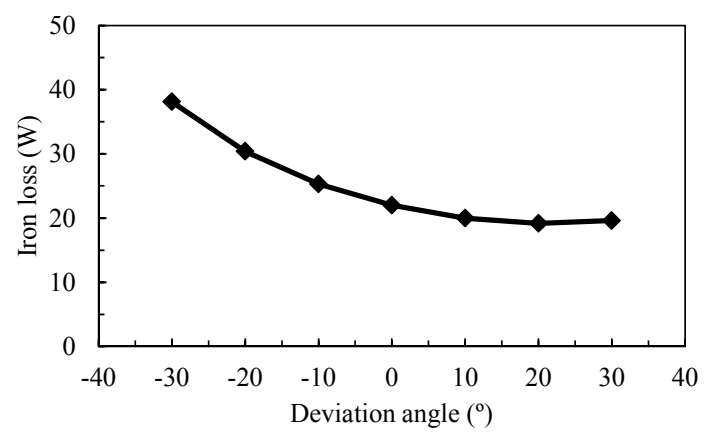

(b)

Fig. 7. Losses by different deviation angles: (a) Copper loss; (b) Iron loss resistance and stator current, respectively. The total iron losses in the motor represented by the resistance $R_{f}$ and the iron loss current vector $i_{c}$ in the equivalent circuit.

The finite-element method is used to calculate the iron and PM eddy current losses of the LPMV motor. In addition, the copper loss can be calculated by a straightforward way, as given by

$$
P_{C}=\sum_{p=A}^{C}\left(I_{p 1}{ }^{2}+I_{p 2}{ }^{2}\right) R_{p}
$$

where $R_{p}$ and $I_{p}(p=A, B$ and $C$ ) are the motor winding resistances and RMS currents, respectively.

The copper loss results by different deviation angles $\gamma$ is presented in Fig. 7(a). It can be seen that when $\gamma=10^{\circ}$, the copper loss is minimal. Then, once the deviation angle $\gamma$ changes, the copper loss will increase.

In fact, the introduced deviation angle has effect on the main magnetic field of the LPMV motor. Under the same condition, the iron loss changes with different deviation angles are shown in Fig. 7(b). It reflects that the iron loss decrease due to the increased deviation angle. The eddy current losses of LPMV motor are shown in Fig. 8. Considering that the eddy current losses are too small, it can be neglected when calculating the total losses in this work.

In summary, Fig. 9 shows the total losses with different deviation angles. It can be seen that although the iron loss decreases with increased deviation angle, but the total

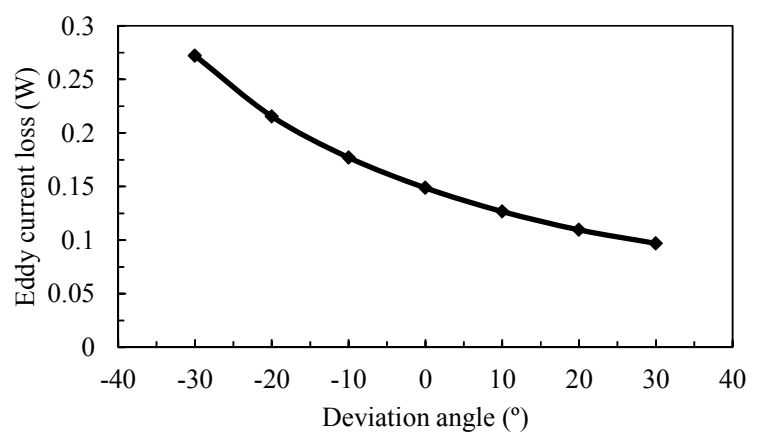

Fig. 8. Eddy current losses

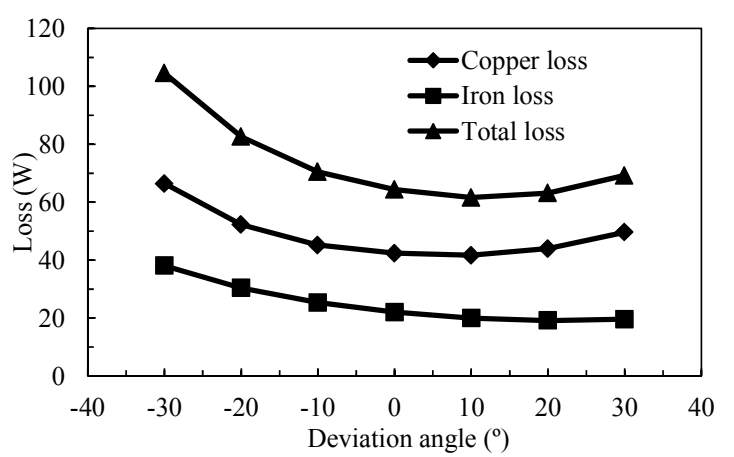

Fig. 9. Copper loss, iron loss and total losses 
losses reach its minimal value at $\gamma=10^{\circ}$. Compare to the point $\gamma=0^{\circ}$, the total losses decreased about $4.5 \%$ at $\gamma=$ $10^{\circ}$.

\section{Simulation}

In Section 2, the optimal current angle has been derived through the loss analysis. Also, the current angle can be applied to the current allocation module as shown in Fig. 4. Based on the developed $d$ - and $q$-axis mathematical model and the field oriented control strategy considering loss minimization, the dynamic simulation model of the LPMV motor and control system are built by using MATLAB/ Simulink, as shown in Fig. 10. It consists of LPMV motor, power circuit, SVPWM sector, calculation sector, current allocation sector, speed controller module, and output display module of the total force performance.

To evaluate the dynamic performance of the proposed close-loop LPMV motor drive, it should be investigated the motor performance under no load, startup on load conditions. Also, the given speed will change, as shown in Fig. 11. The initial state of the given speed is set to zero. At time $t_{0}$, the given speed set as $v_{1}$, then when time is $t_{1}$, the given speed change to $v_{2}$. The control system will be turned off at time $t_{\text {off }}$.

Fig. 12(a) shows the responses of speed, mover position, and current at changeable speed based on no-load condition. At time $t_{0}=0.1 \mathrm{~s}$, the given speed changes from zero to 0.2 $\mathrm{m} / \mathrm{s}$, and the mover speed reaches to $0.2 \mathrm{~m} / \mathrm{s}$ after $0.06 \mathrm{~s}$. At time $t_{1}=0.3 \mathrm{~s}$, the given speed rises to $0.3 \mathrm{~m} / \mathrm{s}$, and the mover speed reaches to $0.3 \mathrm{~m} / \mathrm{s}$ after $0.04 \mathrm{~s}$. Meanwhile, the waveform of position has changed its slope.

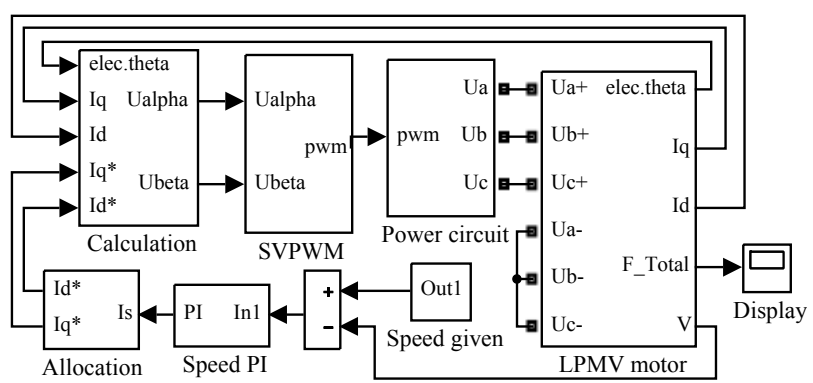

Fig. 10. Field oriented control system of LPMV motor drive

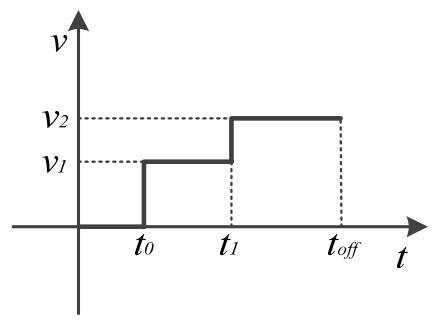

Fig. 11. Signal of given speed
The retarding performance of the motor drive can be observed in the Fig. 12(b), including speed, mover position, and current. It can be seen that the mover starting time is

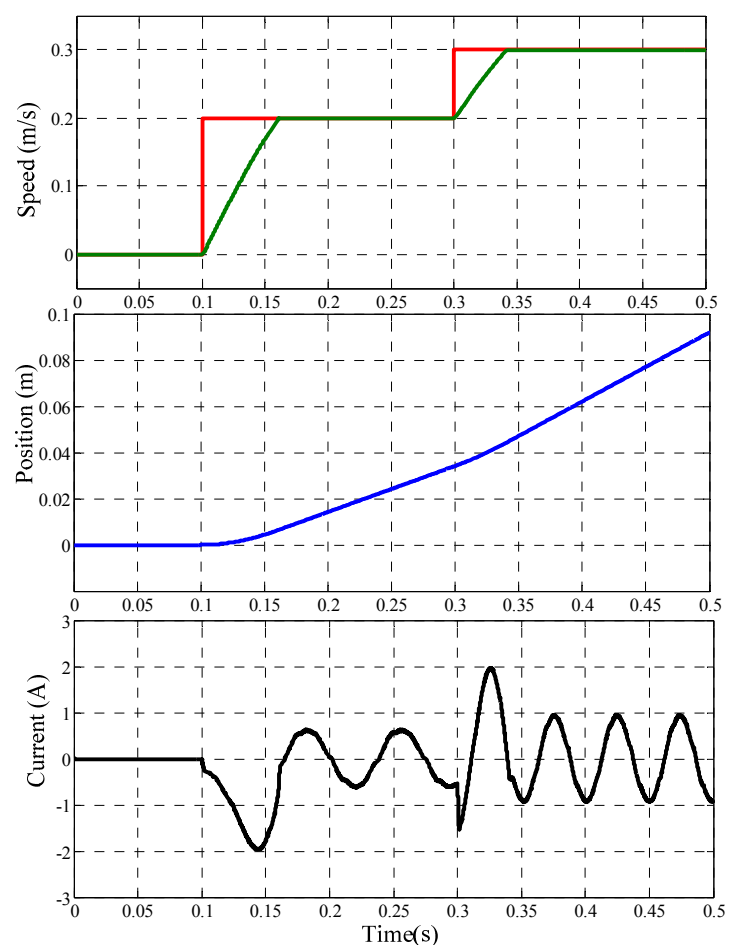

(a)

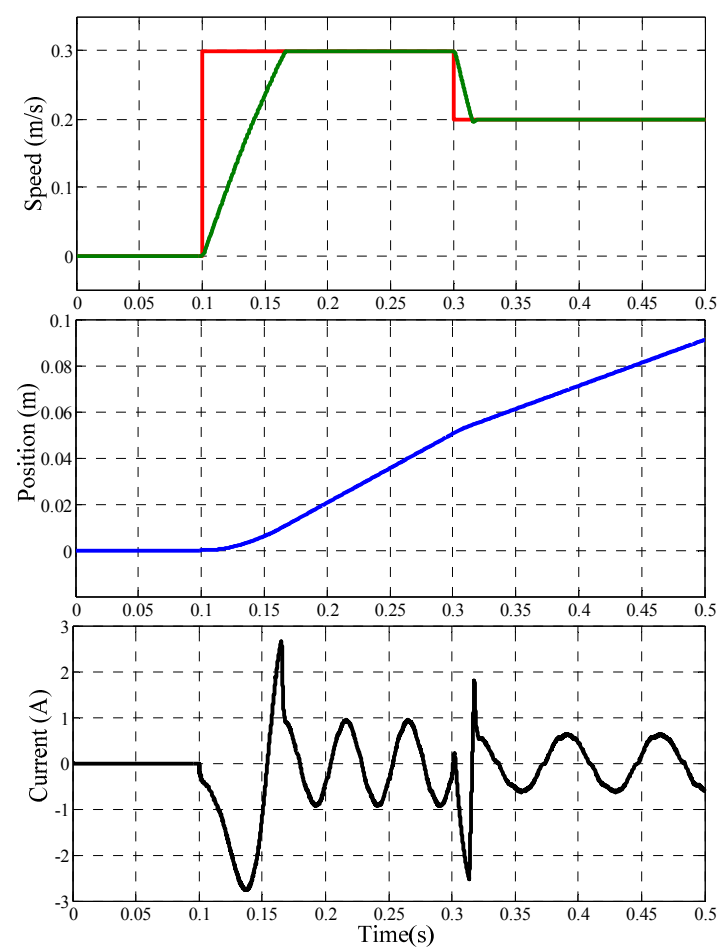

(b)

Fig. 12. No-load responses of speed, mover position, and current with dynamic processes: (a) Given speed $v$ $=0.2 \mathrm{~m} / \mathrm{s}$ switch to $v=0.3 \mathrm{~m} / \mathrm{s}$; (b) Given speed $v=$ $0.3 \mathrm{~m} / \mathrm{s}$ switch to $v=0.2 \mathrm{~m} / \mathrm{s}$ 


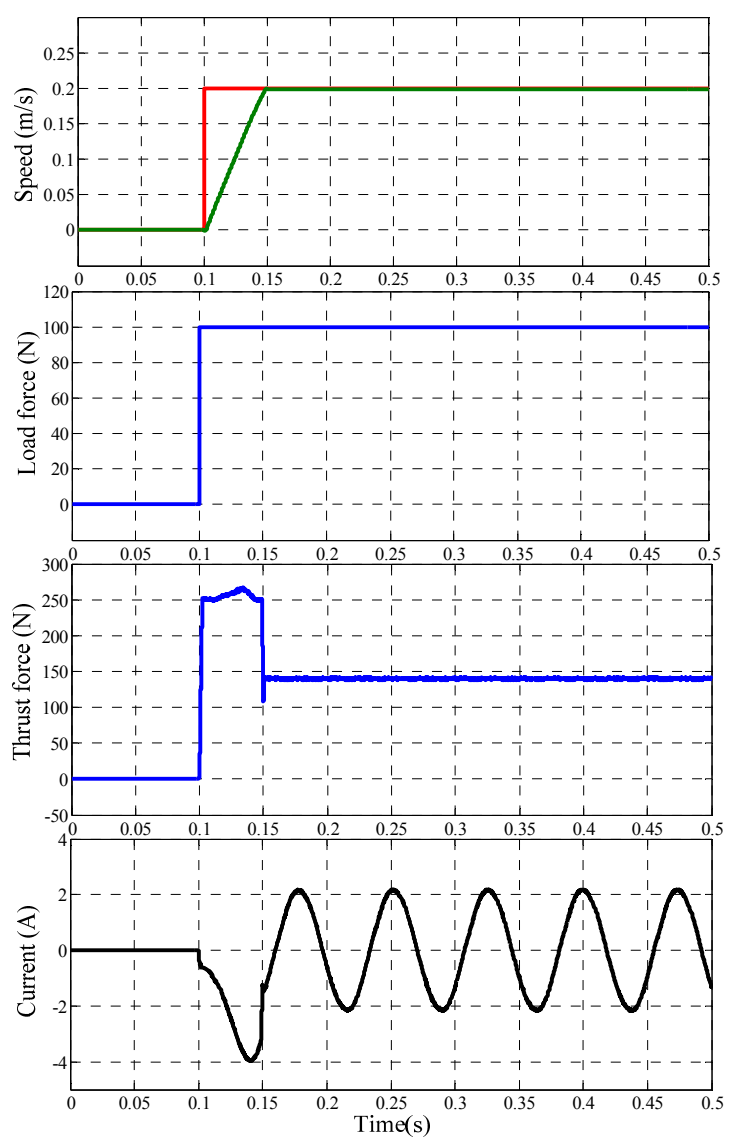

Fig. 13. Simulation waveforms of speed, current and force startup with load condition

$0.06 \mathrm{~s}$, when the given speed equals to $0.3 \mathrm{~m} / \mathrm{s}$. At time $t_{1}$ $=0.3 \mathrm{~s}$, the given speed becomes $0.2 \mathrm{~m} / \mathrm{s}$, and the motor completes the deceleration process taken $0.02 \mathrm{~s}$. Furthermore, the current maintain the same value with the same speed in Fig. 12(a), after a brief shock. Obviously, the proposed motor drive system has good dynamic performance at different given speeds.

Next, the close-loop control performance at startup with load and sudden load change conditions are investigated based on simulation model. Fig. 13 shows the responses of speed, load force, thrust force and current at startup with load condition. At time $t_{0}=0.1 \mathrm{~s}$, the given speed changes from zero to $0.2 \mathrm{~m} / \mathrm{s}$ with the load $F_{L}=100 \mathrm{~N}$, and the mover speed reaches to $0.2 \mathrm{~m} / \mathrm{s}$ after $0.05 \mathrm{~s}$. It can be seen that the peak current maintain at $2.2 \mathrm{~A}$. In addition, the main thrust force is used to drive the load, and a small portion is used to overcome the friction force. Thus, the thrust force maintain in $140 \mathrm{~N}$ at $v=0.2 \mathrm{~m} / \mathrm{s}$.

Fig. 14 shows the simulation responses of speed, load force, thrust force, and current of the motor at $v=0.2 \mathrm{~m} / \mathrm{s}$, and sudden load change with $F_{L}=100 \mathrm{~N}$. It can be observed that the LPMV motor can offer a good regulation at a sudden load change. When the given speed $v=0.2 \mathrm{~m} / \mathrm{s}$ when $t_{0}=0.1 \mathrm{~s}$, it can be seen that the mover speed reaches $0.2 \mathrm{~m} / \mathrm{s}$ after $0.04 \mathrm{~s}$. At time $t_{1}=0.2 \mathrm{~s}$, the load add to $100 \mathrm{~N}$,

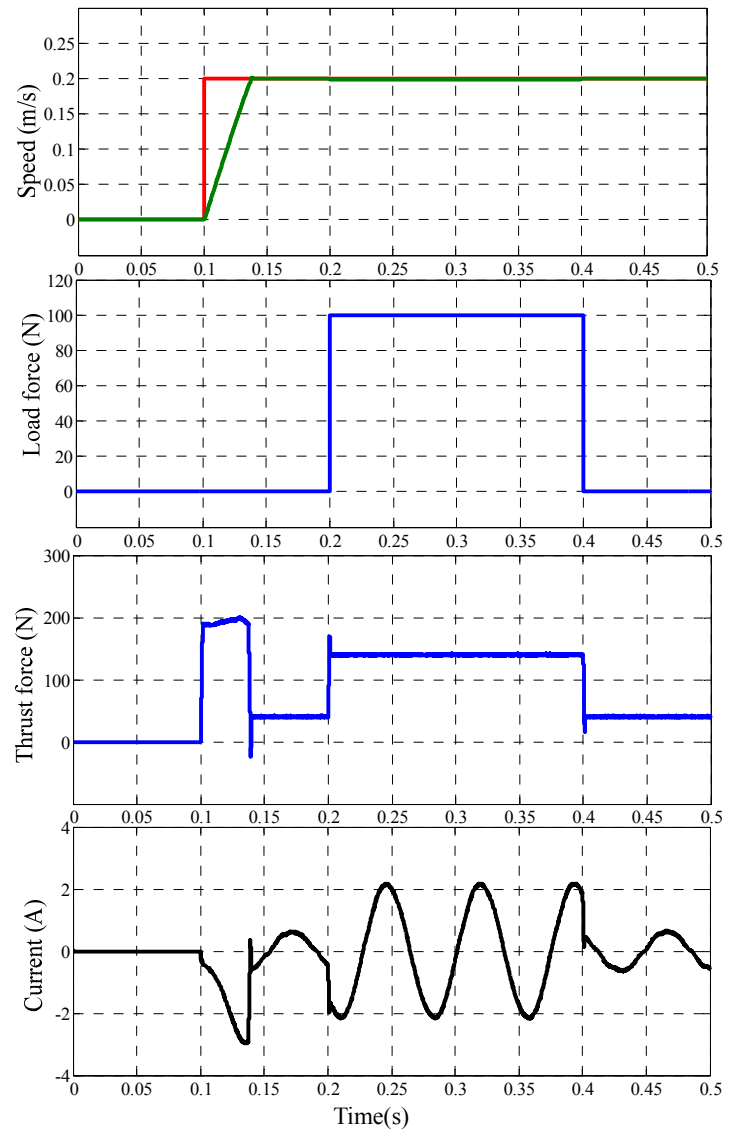

Fig. 14. Simulation waveforms of speed, current and force with sudden change of load

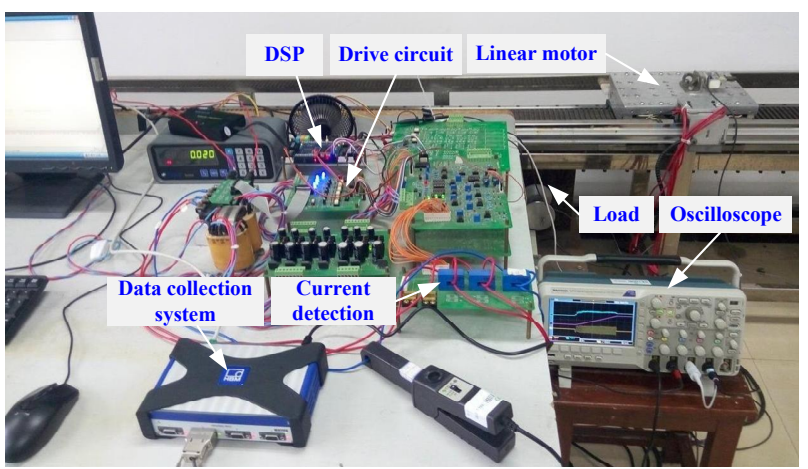

Fig. 15. Prototype of LPMV motor control system

the peak phase of current turn to $2.2 \mathrm{~A}$ from $0.6 \mathrm{~A}$. At the same time, the thrust force increased above $100 \mathrm{~N}$ from 40 $\mathrm{N}$ to $140 \mathrm{~N}$. The simulation results show that the motor has good startup and robust properties at load condition.

\section{Experimental Verification}

To validate the proposed field oriented control, a prototype of the three-phase LPMV motor has been fabricated, and the experiment system has been built, as 
shown in Fig. 15. The system consists of the a force sensor to measure the thrust force, a data collection system to collect the force data and send it to the computer, a magnetic brakes to offer variable load, TMS320F2812 DSP to implement the control strategy, detection circuit to measure the phase current, drive circuit to generate PWM signal.

Fig. 16 shows the three phase current waveforms when the given speed is equal to $0.3 \mathrm{~m} / \mathrm{s}$ at noload, and the current is about $1.9 \mathrm{~A}$. The no-load closed-loop control performances of the LPMV motor are assessed at changeable given speed. Fig. 17(a) shows the measured responses of the speed, distance, and the phase current when the given speed changed from $0.2 \mathrm{~m} / \mathrm{s}$ to $0.3 \mathrm{~m} / \mathrm{s}$ with no-load condition. It should be mentioned that the current

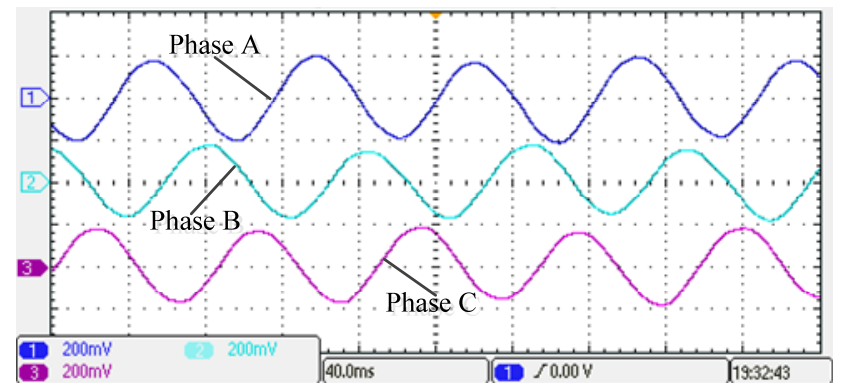

Fig. 16. Three phase current responses of given speed is $0.3 \mathrm{~m} / \mathrm{s}$ with no load.

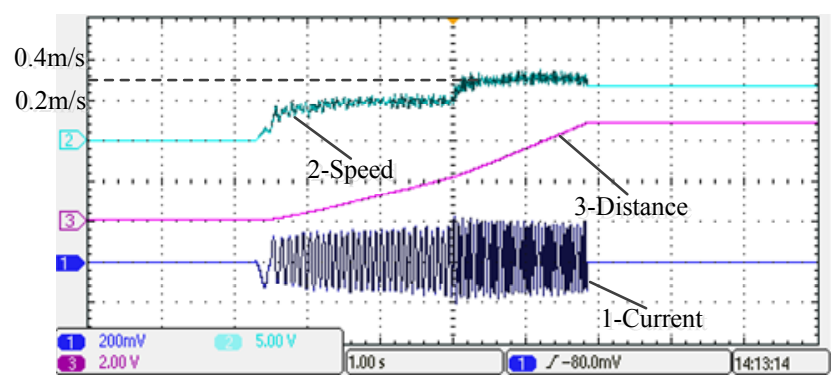

Speed $(0.2 \mathrm{~m} / \mathrm{s} / \mathrm{div})$, Distance $(0.4 \mathrm{~m} / \mathrm{div})$, Current $(2 \mathrm{~A} / \mathrm{div})$, Time $(1 \mathrm{~s} / \mathrm{div})$

(a)

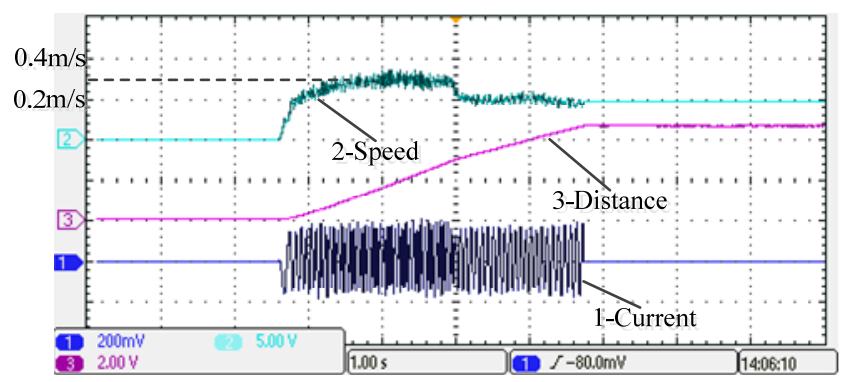

Speed $(0.2 \mathrm{~m} / \mathrm{s} / \mathrm{div})$, Distance $(0.4 \mathrm{~m} / \mathrm{div})$, Current $(2 \mathrm{~A} / \mathrm{div})$, Time $(1 \mathrm{~s} / \mathrm{div})$

(b)

Fig. 17. Measured responses of speed, mover position, and current at a changeable given speeds condition with on load. (a) Given speed $0.2 \mathrm{~m} / \mathrm{s}$ switch to $0.3 \mathrm{~m} / \mathrm{s}$. (b) Given speed $0.3 \mathrm{~m} / \mathrm{s}$ switch to $0.2 \mathrm{~m} / \mathrm{s}$ stable at 1.6 A gradually, when the given speed is $0.2 \mathrm{~m} / \mathrm{s}$. which is caused by the friction force. When the given speed changed to $0.3 \mathrm{~m} / \mathrm{s}$, the current have a small increase, because the value of friction force are related to the mover speed, then stable at $1.9 \mathrm{~A}$.

To evaluate the retard performance of the proposed field oriented control strategy, Fig. 17(b) shows the measured waveforms of the speed, distance, and phase current when the given speed changed from $0.3 \mathrm{~m} / \mathrm{s}$ to $0.2 \mathrm{~m} / \mathrm{s}$, respectively, at no-load. The startup time is about $0.2 \mathrm{~s}$, when the mover speed equals to $0.3 \mathrm{~m} / \mathrm{s}$. Besides, the distance waveform slope smaller than before when the given speed changes to $0.2 \mathrm{~m} / \mathrm{s}$. Finally, the current from different given speeds maintain the same value with the Fig. 17(a).

To validate the dynamic performance of the LPMV motor at load condition, the speed control responses of the motor startup with load condition and at sudden load condition, as shown in Figs. 18 and 19. The motor load connected with the mover through the force sensor.

Fig. 18(a) shows the experiment responses of speed, distance and the phase current of the motor, when the given speed is $0.2 \mathrm{~m} / \mathrm{s}$. The motor start at $t=8 \mathrm{~s}$ and reaches 0.2 $\mathrm{m} / \mathrm{s}$ after $1 \mathrm{~s}$. When the motor stops, the mover position is about $1 \mathrm{~m}$. Meanwhile, when the load increases, the peak of the phase current changes and maintains a constant value 2.8 A eventually. Fig. 18(b) shows the load force change waveform. When the motor start to move, the steel

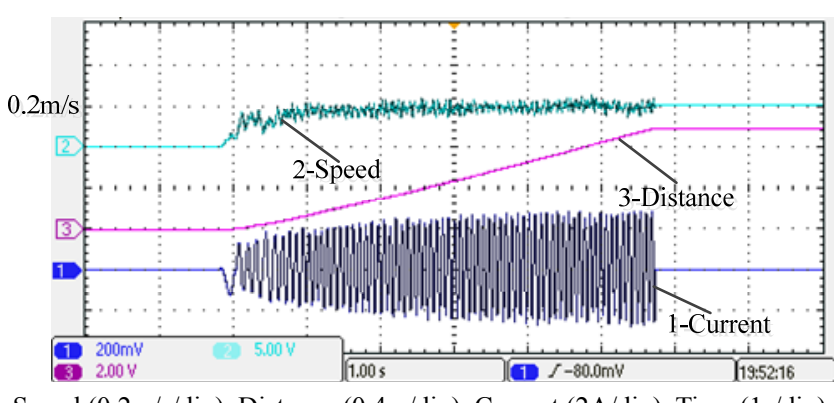

Speed $(0.2 \mathrm{~m} / \mathrm{s} / \mathrm{div})$, Distance $(0.4 \mathrm{~m} / \mathrm{div})$, Current $(2 \mathrm{~A} / \mathrm{div})$, Time $(1 \mathrm{~s} / \mathrm{div})$

(a)

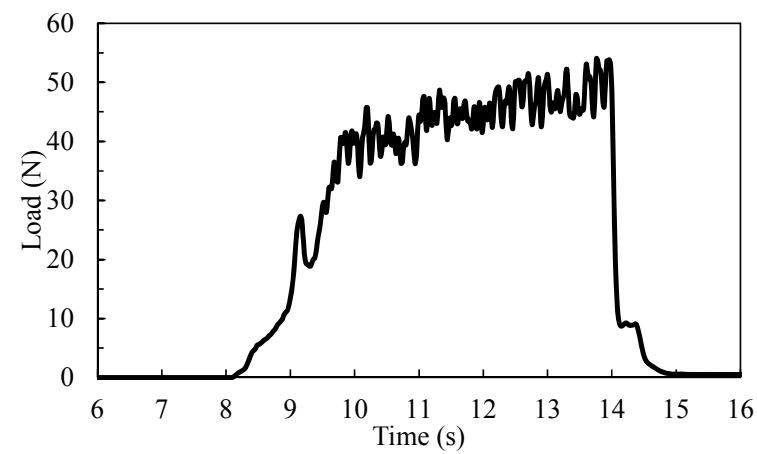

(b)

Fig. 18. Measured responses of given speed is $0.2 \mathrm{~m} / \mathrm{s}$ and start with load: (a) Speed, distance and the phase current; (b) Load force 


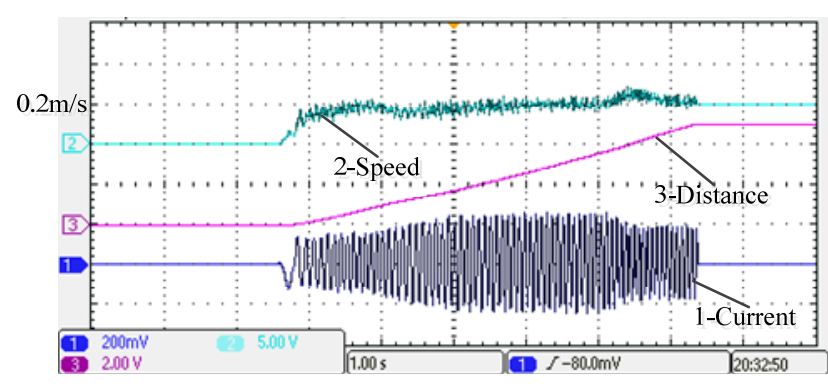

Speed $(0.2 \mathrm{~m} / \mathrm{s} / \mathrm{div})$, Distance $(0.4 \mathrm{~m} / \mathrm{div})$, Current $(2 \mathrm{~A} / \mathrm{div})$, Time $(1 \mathrm{~s} / \mathrm{div})$

(a)

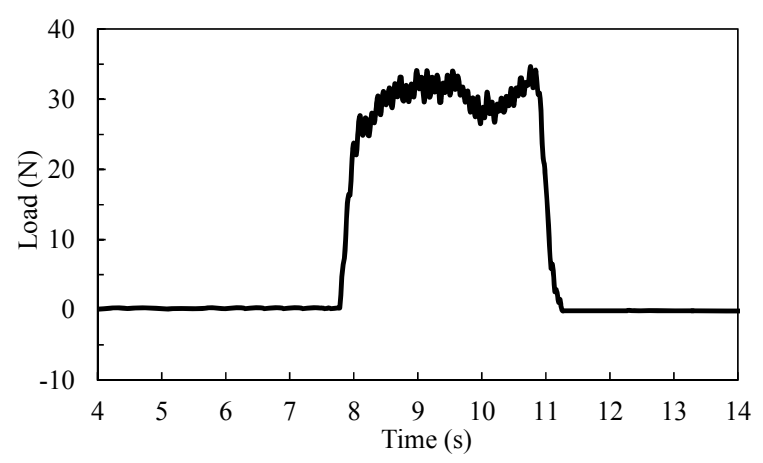

(b)

Fig. 19. Measured responses of given speed is $0.2 \mathrm{~m} / \mathrm{s}$ operate with a sudden load: (a) Speed, distance and the phase current; (b) Sudden load force

wire rope become taut. It can be seen that a sudden rise and a sudden fall lasted $0.2 \mathrm{~s}$, then increases until $53 \mathrm{~N}$.

Fig. 19(a) shows the experiment responses of speed, distance and the phase current of the motor, at a sudden change load condition, when the given speed is $0.2 \mathrm{~m} / \mathrm{s}$. The motor starts at $t=6.6 \mathrm{~s}$. After a startup time equals to $0.8 \mathrm{~s}$, the mover speed reaches the given speed. As shown in Fig. 19(a), the mover speed maintains a stable value, and the peak value of phase current changes as the load changes. Fig. 19(b) shows the sudden load force change. It can be seen that the load force rises suddenly at $t=8 \mathrm{~s}$ and drops to zero at $t=11 \mathrm{~s}$. During the start and the stop, it has a fluctuation caused by the load equipment.

\section{Conclusion}

This paper have proposed a new control strategy for a LPMV motor based on mover field oriented SVPWM control strategies, in which the motor losses are minimized. The $d$ - and $q$-axis and the mathematical model of the LPMV motor have been defined and developed, respectively. Then, the field oriented control system and loss model of the LPMV motor have been built. The noload and load dynamic performance of the motor at closed loop speed control strategies has been investigated to verity the proposed control strategy. The simulated and experimental results have verified that the control system can minimize the motor loss by using the proposed optimal current distribution method, and the motor can also offer a good dynamic performance.

\section{Acknowledgements}

This work was supported in part by the National Natural Science Foundation of China (51422702 and 51277194), by the Qing Lan Project of Jiangsu Province, the Graduate Education Innovation Project of Jiangsu Province (SJZZ150132), and by the Priority Academic Program Development of Jiangsu Higher Education Institutions.

\section{References}

[1] K. Suzuki, Y. J. Kim, and H. Dohmeki, "Driving Method of Permanent Magnet Linear Synchronous Motor with the Stationary Discontinuous Armature for Long-distance Transportation System," IEEE Trans. Ind. Electron., vol. 59, no. 5, pp. 2227-2235, May 2012.

[2] H. W. Lee, C. B. Park, and B. S. Lee, "Thrust Performance Improvement of a Linear Induction Motor," J. Electr. Engin. Tech., vol. 6, no. 1, pp. 81$85,2011$.

[3] N. Hodgins, O. Keysan, A. S. McDonald, and M. A. Mueller, "Design and Testing of a Linear Generator for Wave-energy Applications," IEEE Trans. Ind. Elec-tron., vol. 59, no. 5, pp. 2094-2103, Jul. 2013.

[4] R. Hellinger and P. Mnich, "Linear Motor-powered Transportation: History, Present Status, and Future Outlook," Proc. IEEE, vol. 97, no. 11, pp. 1892-1900, Nov. 2009.

[5] M. Carpita, T. Beltrami, C. Besson, and S. Gavin, "Multiphase active way linear motor: Proof-ofconcept prototype," IEEE Trans. Ind. Electron., vol. 59, no. 5, pp. 2178-2188, May 2012.

[6] A. Goto, T. Okamoto, A. Ikariga, T. Todaka, and M. Enokizono, "A new moving-magnet type linear actuator utilizing flux concentration permanent magnet arrangement," J. Electr. Engin. Tech., vol. 7, no. 3, pp. 342-348, 2012.

[7] W. X. Zhao, M. Cheng, K. T. Chau, R. W. Cao, and J. H. Ji, "Remedial injected-harmonic-current operation of redundant flux-switching permanent-magnet motor drives." IEEE Trans. Ind. Electron., vol. 60, no. 1, pp. 151-159, Jan. 2013.

[8] K. Okada, N. Niguchi, and K. Hirata, "Analysis of a vernier motor with concentrated windings," IEEE Trans. Magn., vol. 49, no. 5, pp. 2241-2244, May 2013.

[9] M. Cheng, K. T. Chau, and C. C. Chan, "Design and 
analysis of a new doubly salient permanent magnet motor," IEEE Trans. Magn., vol. 37, no. 4, pp. 30123020, Jul. 2001.

[10] R. W. Cao, C. Mi, and M. Cheng, "Quantitative comparison of flux-switching permanent magnet motors with interior permanent magnet motor for EV, HEV, and PHEV applications," IEEE Trans. Magn., vol. 48, no. 8, pp. 2374-2384, Aug. 2012.

[11] M. Cheng, K. T. Chau, C. C. Chan, E. Zhou, and X. Huang, "Nonlinear varying-network magnetic circuit analysis for doubly salient permanent magnet motors," IEEE Trans. Magn., vol. 36, no. 1, pp. 339-348, Jan. 2010.

[12] M. Cheng, W. Hua, J. Z. Zhang, and W. X. Zhao, "Overview of stator-permanent magnet brushless machines," IEEE Trans. Ind. Electron., vol. 58, no. 11, pp. 5087-5101, Nov. 2011.

[13] J. H. Ji, J. X. Zhao, W. X. Zhao, and Z. Y. Fang, "New high force density tubular permanent magnet motor," IEEE Trans. Appl. Supercond., vol. 24, no. 3, 2014, Art. ID. 5200705.

[14] Y. Du, M. Cheng, K. T. Chau, and et al, "Comparison of linear primary permanent magnet vernier machine and linear vernier hybrid machine," IEEE Trans. Magn., vol. 50, no. 11, Nov. 2014, Art. ID 8202604.

[15] D. K. Jang and J. H. Chang, "Performance comparison of PM synchronous and PM vernier machines based on equal output power per unit volume," $J$. Electr. Engin. Tech., vol. 11, no. 1, pp. 150-156, 2016.

[16] Y. Du, K. T. Chau, M. Cheng, and et al, "Design and analysis of linear stator permanent magnet vernier machines," IEEE Trans. Magn., vol. 47, no. 10, pp. 4219-4222, Oct. 2011.

[17] J. H. Ji, W. X. Zhao, Z. Y. Fang, J. X. Zhao, and J. H. $\mathrm{Zhu}$, "A novel linear permanent magnet vernier machine with improved force performance," IEEE Trans. Magn., vol. 51, no. 8, Aug. 2015, Art. ID. 8106710.

[18] W. X. Zhao, J. Q. Zheng, J. B. Wang, and et al, "Design and analysis of a linear permanent magnet vernier machine with improved force density," IEEE Trans. Ind. Electron., vol. 63, no. 4, pp. 2072-2082, Apr. 2016.

[19] R. W. Cao, M. Cheng, and B. F. Zhang, "Speed control of complementary and modular linear fluxswitching permanent magnet motor," IEEE Trans. Ind. Electron., vol. 62, no. 7, pp. 4056-4064, Jul. 2015.

[20] A. Boucheta, I. K. Bousserhane, A. Hazzab, P. Sicard, and M. K. Fellah, "Speed control of linear induction motor using sliding mode controller considering the end effects," J. Electr. Engin. Tech., vol. 7, no. 1, pp. 34-45, 2012.

[21] V. Vongmanee and V. Monyakul, "Modeling of a compressed air energy electrification by using induction generator based on field oriented control principle," J. Electr. Engin. Tech., vol. 9, no. 5, pp. 1511-1519, 2014.

[22] S. Niu, S. L. Ho, and W. N. Fu, " A novel stator and rotor dual permanent magnet vernier motor with space vector pulse width modulation," IEEE Trans. Magn., vol. 50, no. 2, pp. 805-808, Feb. 2014.

[23] C. Mademlis, J. Xypteras, and N. Margaris, "Loss minimization in surface permanent-magnet synchronous motor drives," IEEE Trans. Ind. Electron., vol. 47, no. 1, pp. 115-122, Feb. 2000.

[24] C. Mademlis and N. Margaris, "Loss minimization in vector-controlled interior permanent magnet synchronous motor drives," IEEE Trans. Ind. Electron., vol. 49, no. 6, pp. 1344-1347, Dec. 2002.

[25] J. G. Lee, K. H. Nam, S. H. Lee, S. H. Choi, and S. W. Kwon, "A Lookup Table Based Loss Minimizing Control for FCEV Permanent Magnet Synchronous Motors," J. Electr. Engin. Tech., vol. 4, no. 2, pp. 201-210, 2009.

[26] C. C. Mi, G. R. Slemon, and R. Bonent, "Minimization of Iron Losses of Permanent Magnet Synchronous Machines," IEEE Trans. Energy Convers., vol. 20, no. 1, Mar. 2005.

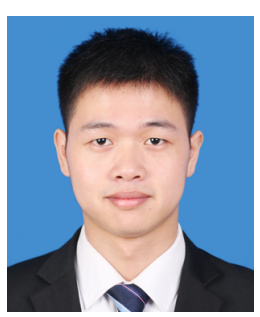

Xianqun Qiu He received B.S. degree from Jiangsu University in 2014, where he is currently pursuing the M.S. degree in electrical engineering. His research interests include drive and control of permanent-magnet motors.

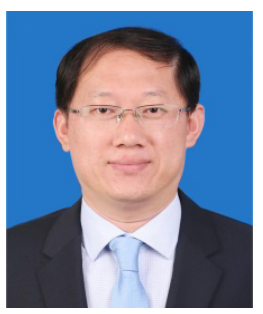

Wenxiang Zhao He received the B.Sc. and M.Sc. degrees in electrical engineering from Jiangsu University, Zhenjiang, China, in 1999 and 2003, respectively, and the $\mathrm{Ph} . \mathrm{D}$. degree in electrical engineering from Southeast University, Nanjing, China, in 2010. He has been with Jiangsu University since 2003, where he is currently a Professor with the School of Electrical Information Engineering. From 2008 to 2009, he was a Research Assistant with the Department of Electrical and Electronic Engineering, University of Hong Kong, Hong Kong. From 2013 to 2014, he was a Visiting Professor with the Department of Electronic and Electrical Engineering, University of Sheffield, Sheffield, U.K. His current research interests include electric machine design, modeling, fault analysis, and intelligent control. $\mathrm{He}$ has authored and co-authored over 130 technical papers in these areas. 


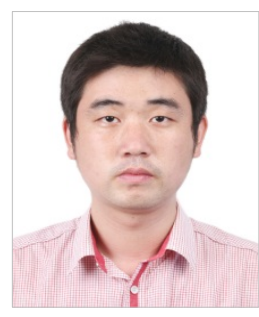

Qian Chen He received the B.Sc. and $\mathrm{Ph} . \mathrm{D}$. degrees from Jiangsu University, Zhenjiang, China, in 2009 and 2015, respectively, in electrical engineering and control engineering. He has been with Jiangsu University since 2015, where he is currently a Lecturer in the School of Electrical Information Engineering. His current research interests include electric machine design, modeling, fault analysis, and intelligent control.

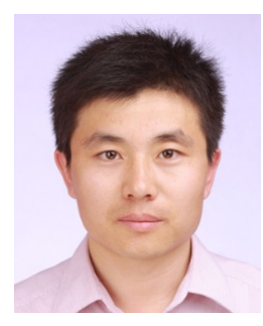

Dezhi Xu He received the B.Sc. degree in electrical engineering from Hebei University of Science \& Technology, Shijiazhuang, China, in 2003, the M.Sc. degree in electrical engineering from Guizhou University, Guiyang, China, in 2006, and the Ph.D. degree in electrical engineering from Shanghai University, Shanghai, China, in 2015. He has been with Jiangsu University since 2015, where he is currently a Lecturer in the School of Electrical Information Engineering. His current research interests include permanentmagnet motor drives and power electronics. 